\title{
Valuasi Ekonomi Taman Wisata Alam Gunung Pancar Kabupaten Bogor
}

Tatan Sukwika a, 1, Hendrietta Kasih a, 2

${ }^{1}$ tatan.swk@gmail.com, ${ }^{2}$ hendriettakasih@gmail.com

a Program Studi Teknik Lingkungan, Universitas Sahid Jakarta, Jl. Prof.Dr. Seopomo No. 84, DKI Jakarta, Indonesia

\begin{abstract}
Mount Pancar Nature Park (TWAGP) was located in Karang Tengah Village, Babakan Madang District, Bogor Regency. As a unity of sustainability, the TWAGP ecosystem must be able to provide benefits with various values. In the context of the valuation approach, of course, there are practical and normative dimensions for selecting ecosystem services. This study aimed to determine the factors that affect the number of visits to TWAGP and calculate the economic valuation of TWAGP based on the travel cost method (TCM). The method used was TCM. This method was calculated based on total consumer surplus, the coefficient of travel expenses, and total visits respondents. The analysis showed that four factors influence visit frequency, to TWAGP including, cost of travel, level of education, length of knowledge and distance travelled. The consumer surplus of individuals per visit was Rp209.000, and the total economic value was Rp8.535.978.000. The recommendation is a response to the willingness of visitors to pay an additional entry fee than what enforced needs to followed by improving the quality of tourist attractions so that visitors are satisfied and increasingly want to return to visit.
\end{abstract}

Keyword: Consumer surplus, Economic valuation, Mount pancar nature park, Sustainability, Travel cost method

\section{PENDAHULUAN}

Indonesia telah disebut sebagai mega biodiversity country karena keanekaragaman jenis flora dan fauna serta karakteristik kekayaan hayati tersebar dari sabang sampai merauke yang tidak dimiliki negara lain seperti panorama pegunungan, sungai, air terjun, hingga keindahan persawahan dan perkebunan. (Bappenas, 2016). Potensi nilai ekonomi yang tinggi dari sumber daya pariwisata tersebut diatas harus dikembangkan menjadi salah satu penggerak ekonomi dan kelestarian lingkungan melalui taman wisata. Beberapa penelitian telah membuktikan bahwa peran sektor pariwisata menjadi penggerak pertumbuhan ekonomi melalui pajak, membuka lapangan pekerjaan dan menstabilkan perekonomian lokal (Cárdenas-García et al., 2015; Tripomo \& Soesatyo, 2014)

Disebutkan dalam undang-nndang nomor 5 tahun 1990 bahwa taman wisata alam adalah kawasan pelestarian alam yang terutama dimanfaatkan untuk pariwisata dan rekreasi alam. Salah satu kawasan pelestarian alam di Indonesia yaitu Taman Wisata Alam Gunung Pancar (TWAGP) yang berada di Kabupaten Bogor. TWAGP memiliki potensi wisata alam yang hingga saat ini menjadi daerah tujuan wisata. TWAGP memiliki daya tarik seperti layanan menikmati keindahan hutan pinus dan relaksasi berendam di pemandian air panas alam. Pengunjung TWAGP meningkat dari tahun ke tahunnya. Tahun 2017 jumlah pengunjung TWAGP sebanyak 40.458 orang dan tahun 2018 meningkat menjadi 40.842 orang. Seiring waktu, fenomena kenaikan jumlah pengunjung perlu diringi dengan adanya pengembangan dan pengelolaan terhadap TWAGP.

Ditetapkan kawasan gunung pancar menjadi TWAGP oleh pemerintah daerah Kabupaten Bogor karena kawasan tersebut secara ekosistem memiliki potensi secara ekonomi dari sektor pariwisata. Ekosistem memberikan manfaat dengan berbagai macam nilai. Dalam konteks pendekatan valuasi secara luas, didalam ada dimensi praktis dan normatif untuk menyeleksi jasa-jasa ekosistem (Gómez-Baggethun \& Ruiz-Pérez, 2011). Dalam konsep pembangunan berkelanjutan, perlunya kepastian upaya pelestarian antara konservasi sumberdaya alam dan pembangunan ekonomi. Pencapaian ini bisa dilakukan melalui valuasi ekonomi sebagai alat meningkatan public awareness pada lingkungan. Hasil valuasi ekonomi oleh Iasha et al. (2015) ternyata bisa memberikan wawasan tentang kemungkinan kenaikan biaya masuk untuk meningkatkan konservasi. Pengukuran nilai ekonomi kawasan hutan wisata dengan metode valuasi ekonomi yaitu travel cost method (TCM). Secara prinsip, TCM digunakan untuk menghasilkan model permintaan, sedangkan konsep surplus konsumen digunakan untuk penentuan nilai dan perbandingan (Matthew et al., 2019). TCM menghitung besarnya biaya pengeluaran oleh pengunjung selama melakukan kegiatan wisata untuk mengestimasi nilai ekonomi sumberdaya alam dan lingkungan sebagai objek wisata. Faktor intensitas kunjungan dan pengaruh lainnya didentifikasi untuk pengelolaan yang lebih baik di masa mendatang. Melalui penelitian ini diharapkan dapat diketahui kesediaan pengunjung dalam hal membayar tiket. Tujuan studi adalah menetukan faktor pengaruh terhadap jumlah kunjungan ke TWAGP dan menghitung valuasi ekonomi TWAGP berdasarkan metode biaya perjalanan.

\section{METODE PENELITIAN}

\section{Tempat dan Waktu Penelitian}

Penelitian dilaksanakan di kawasan TWAGP berlokasi di desa Karangtengah, kecamatan Babakan Madang, kabupaten Bogor, Jawa Barat (Gambar 2). Letak kawasan TWAGP berada pada koordinat $106^{\circ} 54^{\prime} 13^{\prime \prime}-106^{\circ} 54^{\prime} 58^{\prime \prime}$ BT dan 6 6 $35^{\prime} 30^{\prime \prime}-6^{\circ} 35^{\prime} 38^{\prime \prime}$ LS (Gambar 1). Lokasi dipilih dengan sengaja (purposive). Penentuan data secara sampling dan pengambilan data dilaksanakan di bulan Agustus Oktober 2019. 


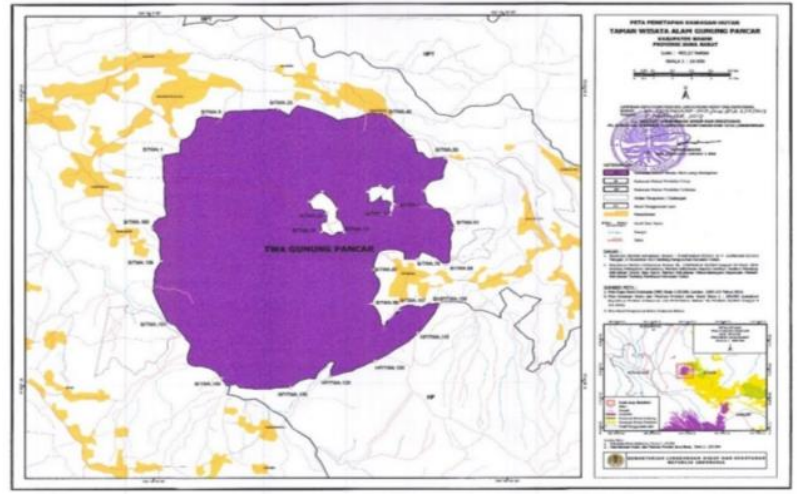

Gambar 1. Peta Lokasi TWAGP Kabupaten Bogor Sumber: Peneliti (2020)
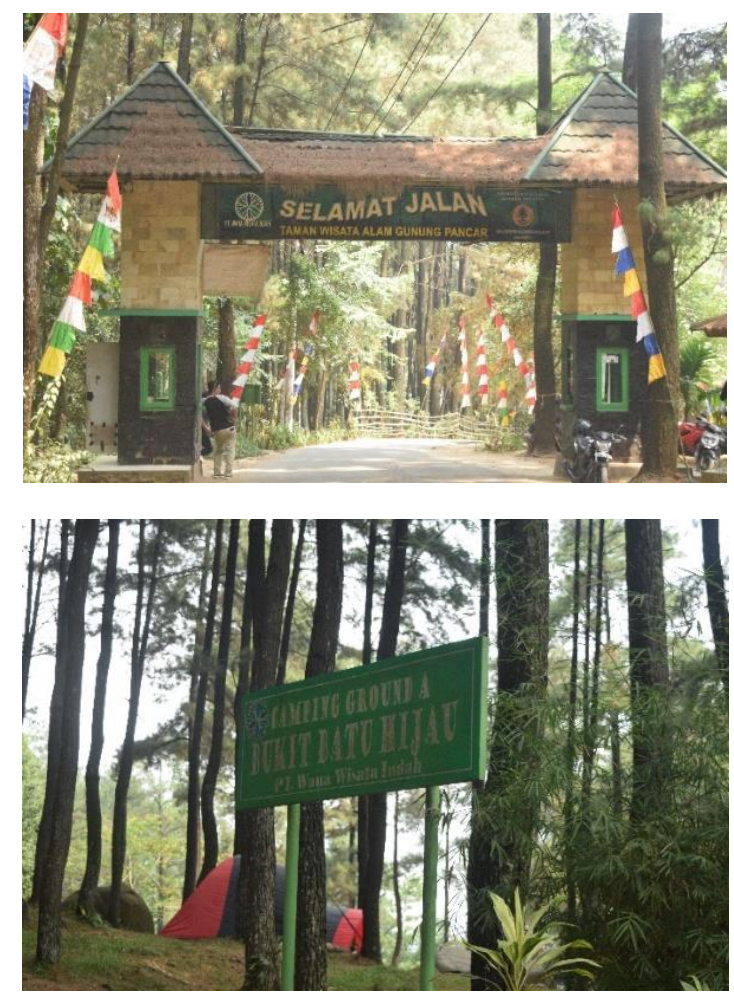

Gambar 2. Kondisi Lokasi TWAGP Kabupaten Bogor Sumber: Peneliti (2020)

\section{Jenis dan Sumber Data}

Jenis data yang digunakan adalah data primer dan sekunder, menurut Sugiyono (2013) data primer dapat diambil langsung melalui kegiataan survei dan wawancara kepada wisatawan di kawasan TWAGP, sementara data sekunder diperoleh dari hasil-hasil penelitian dan lembaga terkait dalam studi ini.

\section{Metode Pengambilan Sampel}

Sampel (responden) diambil secara nonprobability sampling, dimana setiap obyek yang diteliti tidak sama kesempatannya untuk terpilih jadi responden (Sugiyono, 2013). Praktik pengambilan sampel dengan purposive, dimana responden ditemui di lokasi sesuai dengan persyaratan kriteria yang dikehendaki, yaitu berusia diatas 17 tahun (Gambar 3). Menurut data dari pengelola TWAGP, rata-rata jumlah kunjungan periode tahun 2018 adalah 40.842 orang. Berdasarkan data tersebut dengan rumus slovin diketahui jumlah sampelnya sebanyak 100 responden dengan confidence level $90 \%$ atau batas kesalahan sebesar 10\%. Secara teknis, penggunaan rumus Slovin sebagai berikut (Sugiyono, 2013):

$$
\begin{gathered}
n=\frac{N}{1+n e^{2}} \\
n=\frac{40842}{1+40842 \times 0,1^{2}}=99,75=100 \\
\mathrm{~N}=\quad \text { ukuran populasi } \\
\mathrm{n}=\quad \text { ukuran sampel } \\
\mathrm{e}=\quad \text { presisi, margin of error }=10 \%
\end{gathered}
$$
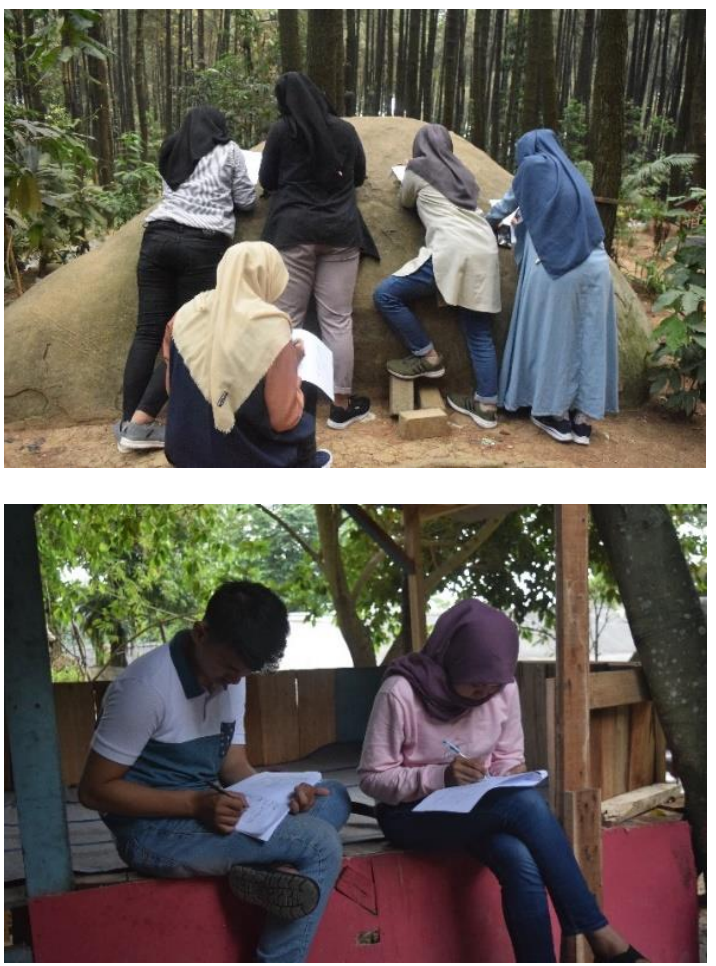

Gambar 3. Situasi Pengisian Kuisioner di Lokasi TWAGP

Sumber: Peneliti (2020)

\section{Pengolahan dan Alat Analisis Data}

Data yang terkumpul diolah dan dianalisis secara kualitatif dan kuantitatif (Sugiyono, 2013). Penggunaan kedua metode analisis data ini untuk memberikan pemecahan rumusan masalah dalam penelitian yang dilakukan. Pada penentuan faktor-faktor yang mempengaruhi jumlah kunjungan ke TWAGP digunakan analisis regresi linier berganda dengan minitab15. Sedangkan penghitungan nilai ekonomi TWAGP berdasarkan metode biaya perjalanan atau travel cost method (TCM) digunakan microsoft excel untuk membantu analisis deskriptif baik secara kualitatif maupun kuantitatif. Data yang dianalisis bersumber dari hasil wawancara responden menggunakan kuesioner. Pada penelitian ini terdapat dua pendugaan yang dianalisis yaitu:

a. Pendugaan jumlah kunjungan

Pendugaan jumlah kunjungan per individu per tahun kunjungan ke TWAGP digunakan TCM. Fungsi 
Vol. 8 No 2, 2020

permintaan terbentuk dari model regresi linier berganda, persamaannya yaitu:

$$
\begin{aligned}
Y & =\beta_{0}+\beta_{1} X_{1}+\beta_{2} X_{2}+\beta_{3} X_{3}+\beta{ }_{4} X_{4}+\beta_{5} X_{5}+\beta_{6} X_{6}+\beta{ }_{7} X_{7} \\
& +\beta_{8} X_{8}+\beta_{9} X_{9}
\end{aligned}
$$

Keterangan:

$$
\begin{aligned}
\mathrm{Y} & =\text { Jumlah kunjungan (kali) } \\
\mathrm{X}_{1} & =\text { Biaya perjalanan (Rp) } \\
\mathrm{X}_{2} & =\text { Total penghasilan (Rp/bulan) } \\
\mathrm{X}_{3} & =\text { Tingkat pendidikan (tahun) } \\
\mathrm{X}_{4} & =\text { Umur (tahun) } \\
\mathrm{X}_{5} & =\text { Lama mengetahui (tahun) } \\
\mathrm{X}_{6} & =\text { Jenis kelamin } \\
\mathrm{X}_{7} & =\text { Waktu tempuh (jam) } \\
\mathrm{X}_{8} & =\text { Waktu di lokasi } \\
\mathrm{X}_{9} & =\text { Jarak tempuh } \\
\beta_{0} & =\text { Konstanta } \\
\beta_{1-9} & =\text { Koefisien regresi } \\
\varepsilon & =\text { Error }
\end{aligned}
$$

b. Pendugaan surplus konsumen

Pendugaan nilai surplus konsumen per individu per tahun dilakukan dengan perhitungan nilai ekonomi dengan metode biaya perjalanan atau TCM. Adapun formulasinya sebagai berikut:

$$
W T P \approx S K=\frac{N^{2}}{2 b_{1}}
$$

Keterangan:

SK = Surplus Konsumen

$\mathrm{N}=$ Jumlah Kunjungan Koresponden

$\mathrm{b}_{1}=$ Koefisien Biaya Perjalanan

$$
S K^{\prime}=\frac{S K / \sum N}{n}
$$

Keterangan:

SK' = Surplus Konsumen/Individu/Perkunjungan

$\mathrm{n}=$ Jumlah Responden

$$
E V=S K^{\prime *} K
$$

Keterangan:

$\mathrm{EV}=$ Nilai Ekonomi per Tahun

SK' = Surplus Konsumen/Individu/Perkunjungan

$\mathrm{K}$ = Estimasi Kunjungan per Tahun

\section{HASIL DAN PEMBAHASAN}

Pada proses analisis ini dilakukan pendekatan uji asumsi klasik seperti uji normalitas, multikolinearitas, dan heterokesdastisitas. Pendekatan ini digunakan sebagai syarat penggunaan model regresi agar hasil regresi yang diperoleh merupakan estimasi yang tepat. Pengukuran uji normalitas (statistik non-parametrik) digunakan onesampel kolmogrof-smirnof test. Nilai $\mathrm{P}$ yang dihasilkan $>0,01$ yakni sebesar 0,150 sementara berdasarkan plot yang dihasilkan secara eksploratif, sebaran data sudah mendekat garis normal. Uji Multikolinearitas diketahui nilai VIF dari setiap variabelnya adalah $<10$ sehingga dapat dimaknai tidak adanya masalah multikolinearitas. Uji heterokesdastisitas digunakan uji breusch-pagan dan dihasilkan nilai $P$ sebesar 0.084 atau $>0,01$ artinya tidak terdapat masalah heterokedastisitas.

\section{Fungsi Permintaan Wisata}

Analisis pasar harus dilakukan sebelum mempromosikan pengembangan pariwisata dan menjamin masyarakat lokal memperoleh manfaat ekonomi yang memadai dari pengembangan pariwisata (Aprilian, 2009; Cárdenas-García et al., 2015; Gómez-

\begin{tabular}{|c|c|c|c|c|c|}
\hline Variabel & Koefisien & $\begin{array}{l}\text { SE Koefi- } \\
\text { sien }\end{array}$ & $\mathrm{T}$ & $\mathrm{P}$ & VIF \\
\hline konstanta & 1,7335 & 0,5861 & 2,96 & 0,004 & \\
\hline $\begin{array}{l}\text { Biaya } \\
\text { Perjalanan }\end{array}$ & $-0,000006$ & 0,000002 & $-4,34$ & $0,000^{*}$ & 2,379 \\
\hline Pendapatan & 0,07735 & 0,08303 & 0,93 & 0,354 & 2,600 \\
\hline $\begin{array}{l}\text { Tingkat } \\
\text { Pendidikan }\end{array}$ & $-0,01159$ & 0,04553 & $-0,25$ & 0,800 & 2,479 \\
\hline Umur & $-0,00626$ & 0,01352 & $-0,46$ & 0,644 & 1,394 \\
\hline $\begin{array}{l}\text { Lama } \\
\text { menge-tahui }\end{array}$ & 0,14605 & 0,02625 & 5,56 & $0,000^{*}$ & 1,249 \\
\hline $\begin{array}{l}\text { Jenis } \\
\text { Kelamin }\end{array}$ & 0,0012 & 0,1435 & 0,01 & 0,993 & 1,151 \\
\hline $\begin{array}{l}\text { Waktu } \\
\text { Tempuh }\end{array}$ & $-0,1952$ & 0,2001 & $-0,98$ & 0,332 & 2,934 \\
\hline $\begin{array}{l}\text { Waktu di } \\
\text { lokasi }\end{array}$ & 0,36081 & 0,08167 & 4,42 & $0,000^{*}$ & 1,179 \\
\hline $\begin{array}{l}\text { Jarak } \\
\text { Tempuh }\end{array}$ & $-0,01634$ & 0,07862 & $-0,21$ & 0,836 & 2,677 \\
\hline $\mathrm{R}^{2}$ & \multicolumn{5}{|c|}{$67,3 \%$} \\
\hline $\mathrm{R}^{2}$ (adj) & \multicolumn{5}{|c|}{$64,1 \%$} \\
\hline
\end{tabular}
Baggethun \& Ruiz-Pérez, 2011). Secara proposional, dari 100 responden pengakuan frekuensi kunjungan ke TWAGP antara kunjungan sekali dengan kunjungan berulang hingga tiga kali kunjungan secara rataan nilainya $30 \%$. Artinya TWAGP merupakan tempat wisata yang berpotensi dikunjungi secara berulang. Fenomena pengulang kunjungan ke TWAGP karena ada faktor cukup aktraktif yaitu pengelola TWAGP menyediakan fasilitas yang dapat digunakan untuk kegiatan seperti camping, outbond, gathering, tracking, downhill, dan photography meskipun ketersediaan sarana dan prasarana masih sangat sederhana. Kepuasan pengunjung lokasi wisata ditentukan oleh keberadaan layanan dan fasilitas yang atraktif (Hironimus et al., 2019; Khisma, 2016; Tripomo \& Soesatyo, 2014).

Tabel 2. Hasil Analisis Regresi Fungsi Permintaan TWAGP dengan TCM

Hasil analisis regresi fungsi permintaan TWAGP dengan TCM diperoleh nilai determinasi $\left(\mathrm{R}^{2}\right)$ dan $\mathrm{R}^{2}$ (adj) masing-masing sebesar $67,3 \%$ dan 64,1\%. Artinya, diversitas demand jumlah kunjungan ke TWAGP dapat dijelaskan oleh $67,3 \%$ variabel bebas pada model dan sisanya dijelaskan oleh variabel yang tidak dimasukkan ke dalam model sebesar 32,7\%. Hasil analisis regresi fungsi permintaan selengkapnya tersaji pada Tabel 2 .

Pehitungan analisis regresi berganda dihasilkan model persamaannya fungsi permintaan TWAGP yaitu:

$$
\begin{gathered}
\mathrm{Y}=1,73-0,000005 \mathrm{X}_{1}+0,0774 \mathrm{X}_{2}-0,0116 \mathrm{X}_{3}-0,0063 \mathrm{X}_{4}+ \\
0,146 \mathrm{X}_{5}+0,001 \mathrm{X}_{6}-0,195 \mathrm{X}_{7}+0,361 \mathrm{X}_{8}-0,0163 \mathrm{X}_{9}
\end{gathered}
$$

Keterangan:

$$
\begin{aligned}
& \mathrm{Y}=\text { Jumlah kunjungan (kali) } \\
& \mathrm{X}_{1}=\text { Biaya perjalanan }(\mathrm{Rp})
\end{aligned}
$$


Vol. 8 No 2, 2020

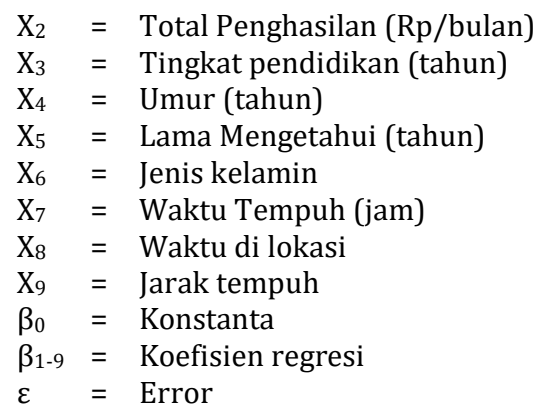

Variabel yang Berpengaruh Signifikan terhadap Permintaan TWAGP

Metode biaya perjalanan (TCM) didasarkan pada teori permintaan dan mengasumsikan bahwa permintaan untuk kasawan wisata berbanding terbalik dengan biaya perjalanan yang harus dihadapi pengunjung tertentu untuk menikmatinya. Berdasarkan uji t, terdapat tiga variabel yang berpengaruh nyata dalam model seperti ditujunkkan oleh nilai P pada Table 2, yaitu:

1. Biaya Perjalanan. Biaya perjalanan menjadi faktor yang penting dimana pengunjung harus mengeluarkan sejumlah biaya dalam suatu kegiatan wisata. Biaya perjalanan adalah segala pengeluaran biaya pengunjung setiap melakukan kegiatan rekreasi antara lain, transportasi, konsumsi, akomodasi, dan biaya tidak terduga lainnya. Analisis regresi menunjukkan biaya variabel perjalanan berpengaruh signifikan pada taraf 1\% dan berhubungan negatif terhadap frekuensi kunjungan. Hubungan negatif tersebut artinya jika biaya perjalanan wisata yang dikeluarkan semakin tinggi maka jumlah kunjungan akan mengalami penurunan ke TWAGP. Hasil analisis diatas sejalan dengan penelitian Limaei et al. (2014) dimana ditemukan hubungan yang signifikan antara jumlah pengunjung dan biaya perjalanan sedangkan saat melakukan perjalanan biaya meningkat, jumlah pengunjung menurun.

2. Lama Mengetahui. Lamanya pengunjung mengetahui keberadaan TWAGP menjadi faktor penentu untuk wisatawan untuk berkunjung ke TWAGP. Hasil analisis menunjukkan bahwa lama seseorang mengetahui lokasi TWAGP berpengaruh signifikan dan positif terhadap frekuensi kunjungan. Artinya, semakin lama seseorang mengenal TWAGP berpotensi tinggi meningkatkan jumlah kunjungan wisatanya. Sejalan dengan penelitian Haban et al. (2017) bahwa tempat wisata yang sudah dikenal lama secara baik perpeluang untuk dikunjungi Kembali dibandingkan diberikan substitusi tempat wisata sejenis namun kurang diketahui.

3. Waktu di lokasi. Salah satu faktor yang mempengaruhi peluang rata-rata frekuensi kunjungan dan ukuran kepuasan wisatawan melakukan kegiatan wisata adalah preferensi wisatawan untuk berlama-lama menghabiskan waktu di lokasi. Hasil analisis menunjukkan bahwa variabel ini memiliki pengaruh signifikan dan positif terhadap frekuensi kunjungan. Hal ini diasumsikan bahwa semakin lama pengunjung menghabiskan waktu di lokasi maka akan meningkatkan potensi jumlah kunjungan selanjutnya. Hal tersebut diduga karena faktor keindahan alam, kesejukan udara serta terdapat fasilitas spot-spot foto yang indah dan menarik sehingga pengunjung merasa nyaman dan berkeinginan untuk kembali berkunjung bahkan berpeluan meningkatkan frekuensi kunjungannya (Gambar 3). Menurut Pradnyana et al. (2015) terdapat hubungan antara kejenuhan dengan objek dan daya tarik wisata alam yang tidak atraktif dan inovatif dengan jumlah ripitasi pengunjung (revisit). Sedangkan Wiratini et al. (2018) menemukan faktor kualitas layanan dan fasilitas objek dan daya tarik wisata yang membosankan berpengaruh kepada niat kunjungan kembali.
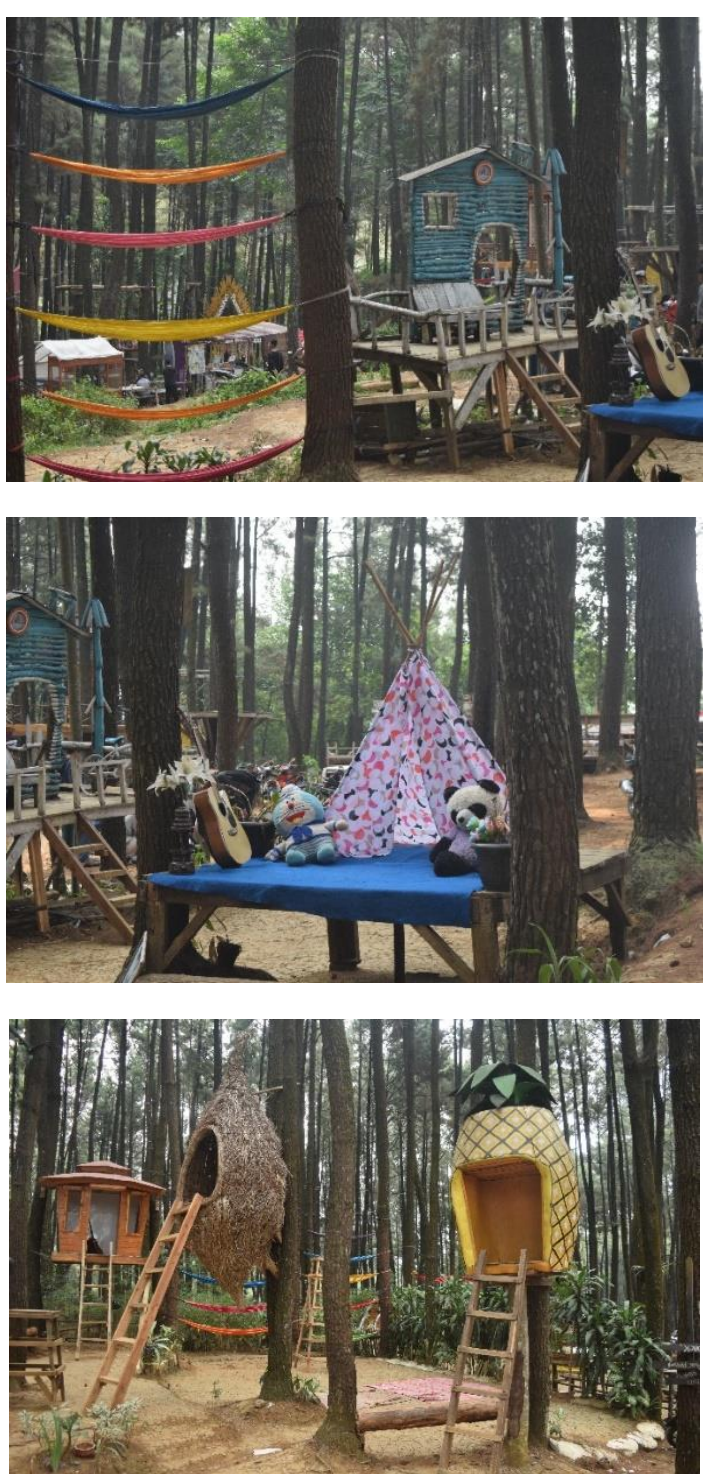

Gambar 3. Keunikan yang Ada di Sekitar Lokasi TWAGP

Sumber: Peneliti (2020)

\section{Surplus Konsumen dan Nilai Ekonomi TWAGP dengan} TCM

Pendugaan surplus konsumen melalui
pendekatan biaya perjalanan yaitu propors pengkuadratan jumlah kunjungan dengan mutiplikasi koefisien biaya perjalanan (Aprilian, 2009; Matthew et al., 2019; Tiwari et al., 2017). Berdasarkan hasil perhitungan menggunakan metode biaya perjalanan diketahui nilai surplus konsumen atau nilai WTP (willingness to pay) 
sebesar Rp209.000 per individu per kunjungan. Nilai surplus konsumen ini diindikasikan sebagai kemampuan pengunjung sebenarnya masih bersedia membayar lebih mahal demi bisa berekreasi atau menikmati pemandangan alam di TWAGP. Sikap kebersediaanya membayar tentunya bersifat kondisional dan berbeda antar tempat wisata, sebagai contoh hasil penelitian Jala dan Nandagiri (2015); dan Amelia (2016) sejalan dengan hasil penelitian diatas, sedangkan Limaei et al. (2014) disebutkan bahwa kesediaan untuk membayar justru menurun dengan meningkatnya biaya masuk.

Selanjutnya, nilai ekonomi hasil multiplikasi dari nilai surplus konsumen dalam penelitiannya ini merupakan total kunjungan selama tahun 2018/2019, yakni sebanyak 40.842 kunjungan. Berdasarkan diperoleh nilai ekonomi sebesar Rp8.535.978.000. Nilai ekonomi hasil perhitungan surplus konsumen lebih jelasnya tersaji dalam Tabel 3.

Tabel 3. Perhitungan Surplus Konsumen

\begin{tabular}{|c|c|r|r|}
\hline Individu & $\begin{array}{c}\text { Y } \\
\text { (Jumlah } \\
\text { Kunjungan } \\
\text { atau N) }\end{array}$ & $\begin{array}{c}\text { Surplus } \\
\text { Konsumen } \\
\text { (SK) } / \text { Individu }\end{array}$ & $\begin{array}{c}\text { Surplus Konsumen } \\
\text { (SK) } / \text { Individu/ } \\
\text { kunjungan }\end{array}$ \\
\hline $01-20$ & 33 & 6.500 .000 & $S N^{2}$ \\
\hline $21-40$ & 35 & 7.300 .000 & 3.300 .000 \\
\hline $41-60$ & 45 & 12.300 .000 & 3.500 .000 \\
\hline $61-80$ & 34 & 7.200 .000 & 4.500 .000 \\
\hline $81-100$ & 62 & 22.000 .000 & 3.400 .000 \\
\hline Jumlah & 209 & 55.300 .000 & 6.200 .000 \\
\hline Mean & & 553.000 & 20.900 .000 \\
\hline Sumber & & & 209.000 \\
\hline
\end{tabular}

Sumber: Hasil Penelitian, 2020

Perhitungan Nilai Ekonomi (EV)

$$
\begin{aligned}
E V & =S K^{*} * \\
& =209.000 \times 42.840 \\
& =8.535 .978 .000
\end{aligned}
$$

\section{KESIMPULAN}

Diketahui terdapat empat faktor yang mempengaruhi frekuensi kunjungan wisata ke TWAGP diantaranya, biaya perjalanan, tingkat pendidikan, lama mengetahui dan jarak tempuh. Berdasarkan pehitungan surplus konsumen menggunakan TCM diperoleh nilai Rp209.000 per individu per kunjungan dan nilai ekonomi lokasi sebesar Rp8.535.978.000. Rekomendasi yang dapat dijadikan perhatian oleh pengelola TWAGP adalah kepuasan pengunjung berhasil diketahui dari kebersediaan membayar penambahan biaya masuk dari yang diberkakukan. Oleh karena itu, pengelola perlu melakukan peningkatan kualitas tempat wisata agar pengunjung puas dan semakin ingin kembali melakukan kunjungan. Keberhasilan tempat tujuan wisata dapat ditentukan melalui indikator kepuasan wisatawan salah satunya ketersediaan pelayanan, akomodasi (Khisma, 2016), infrastruktur (Sukwika, 2018) dan pengembangan kawasan (Hironimus et al., 2019). Penelitian selanjutnya dapat mengambil isu pengelolaan sampah di TWAGP.

\section{UCAPAN TERIMA KASIH}

Ucapan terima kasih ditujukan kepada ibu Laila Febrina, ST, M.Si dan para pihak di lingkungan Program Studi Teknik Lingkungan Fakultas Teknik Unversitas Sahid Jakarta yang telah banyak membantu dan mendukung pada kegiatan penelitian ini.

\section{DAFTAR PUSTAKA}

Amelia, D. (2016). Willingness to pay (WTP) masyarakat DIY terhadap obyek wisata kebun raya dan kebun binatang gembira loka. (Skripsi), Universitas Muhammdiyah Yogyakarta, Yogyakarta.

Aprilian, R. (2009). Analisis permintaan dan surplus konsumen aman wisata alam situ gunung dengan metode biaya perjalanan. (Skripsi), Institut Pertanian Bogor, Bogor.

Bappenas. (2016). Indonesia biodiversity strategy and action plan 2015-2020. Jakarta: Kemeterian Perencanaan Pembangunan Nasional/Bappenas.

Cárdenas-García, P. J., Sánchez-Rivero, M., \& PulidoFernández, J. I. (2015). Does tourism growth influence economic development? Journal of Travel Research, 54(2), 206-221. doi:10.1177/0047287513514297

Gómez-Baggethun, E., \& Ruiz-Pérez, M. (2011). Economic valuation and the commodification of ecosystem services. Progress in Physical Geography, 35, 613628.

Haban, Y., Koleangan, R. A. M., \& Kawung, G. M. V. (2017). Analisis faktor-faktor yang mempengaruhi jumlah kunjungan dan nilai ekonomi kebun raya Bogor. Jurnal Pembangunan Ekonomi dan Keuangan Daerah, 19(1), 1-9. doi:10.35794/jpekd.15775.19.1.2017

Hironimus, Y. S., Rijanta, R., \& Iskandar, D. A. (2019). Faktor-faktor yang mempengaruhi peran aktivitas pariwisata di taman nasional komodo terhadap pertumbuhan ekonomi wilayah kabupaten Manggarai Barat. Region, 14(2), 141153. doi:10.20961/region.v14i2.23280

Iasha, A., Yacob, M. R., Kabir, I., \& Radam, A. (2015). Estimating Economic value for potential ecotourism resources in puncak lawang park, Agam district, West Sumatera, Indonesia. Procedia Environmental Sciences, 30, 326-331. doi:10.1016/j.proenv.2015.10.058

Jala, \& Nandagiri, L. (2015). Evaluation of economic value of pilikula lake using travel cost and contingent valuation methods. Aquatic Procedia, 4, 13151321. doi:10.1016/j.aqpro.2015.02.171

Khisma, T. A. (2016). Dampak kemacetan kota Yogyakarta terhadap kepuasan wisatawan kota Yogyakarta tahun 2016. (Skripsi), Universitas Muhammadiyah Yogyakarta, Yogyakarta.

Limaei, S. M., Ghesmati, H., Rashidi, R., \& Yamini, N. (2014). Economic evaluation of natural forest park using the travel cost method (case study; Masouleh 
Vol. 8 No 2, 2020

forest park, north of Iran). Journal of Forest Science, 60(6), 254-261.

Matthew, N. K., Shuib, A., Ramachandran, S., \& MohammadAfandi, S. H. (2019). Economic valuation using travel cost method (TCM) in kilim karst geoforest park, Langkawi, Malaysia. Journal of Tropical Forest Science, 31(1), 78-89. doi:10.26525/jtfs2019.31.1.7889

Pradnyana, I. G. N. B., Arnawa, I. K., \& Tamba, I. M. (2015). Faktor-faktor yang mempengaruhi kunjungan wisatawan di taman hutan raya Ngurah Rai. AGRIMETA: Jurnal pertanian berbasis keseimbangan ekosistem, 5(10), 42-48.

Sugiyono. (2013). Metode penelitian pendidikan (Pendekatan kuantitatif, kualitatif, dan R\&D). Bandung: Alfabeta.

Sukwika, T. (2018). Peran pembangunan infrastruktur terhadap ketimpangan ekonomi antarwilayah di Indonesia. Jurnal Wilayah dan Lingkungan, 6(2), 115-130. doi:10.14710/jwl.6.2.115-130

Tiwari, S., Nepali, S. C., Paudel, J., \& Upadhaya, S. (2017). Ecotourism in protected a areas of Nepal: An application of individual cost method travel. Research Journal of Agriculture and Forestry, 5(1), 1-6.

Tripomo, R. S., \& Soesatyo, Y. (2014). Pengaruh jumlah wisatawan objek wisata gunung bromo terhadap sektor perdagangan, hotel dan restoran di kabupaten Probolinggo. Jurnal Pendidikan Ekonomi, 2(3), 1-9.

Wiratini, N. N. A., Setiawina, N. D., \& Yuliarmi, N. N. (2018). Analisis faktor-faktor yang mempengaruhi niat kunjungan kembali wisatawan pada daya tarik wisata di kabupaten Badung. E-Jurnal Ekonomi dan Bisnis Universitas Udayana, 7(1), 279-308. 